\title{
HUBUNGAN PERILAKU CARING PERAWAT DENGAN KEPUASAN LAYANAN KEPERAWATAN PADA PASIEN BPJS KESEHATAN DI IRNA 3 RSUD PATUT PATUH PATJU LOMBOK BARAT
}

\author{
Muhammad Asnul Husni ${ }^{1}$, Citra Sepriana ${ }^{2}$, Ageng Abdi Putra ${ }^{3}$, H. Hadi Suryatno ${ }^{4}$ \\ ${ }_{1,2,3,4}$ Sekolah Tinggi Ilmu Kesehatan (STIKES) Mataram \\ citra.sepriana@gmail.com
}

\section{INTISARI}

Perilaku caring merupakan fenomena universal yang mempengaruhi cara manusia berpikir, merasa dan mempunyai hubungan dengan sesama. Seorang perawat harus memiliki perilaku caring dalam pelayanannya terhadap pasien, karena hubungan antara pemberi pelayanan kesehatan dengan pasien merupakan faktor yang mempengaruhi proses kepuasan dan kesembuhan pasien tersebut. Penelitian ini bertujuan untuk mengetahui apakah ada hubungan perilaku caring perawat dengan kepuasan layanan keperawatan pada pasien BPJS kesehatan di IRNA 3 RSUD Patut Patuh Patju Lombok Barat.

Metode penelitian yang digunakan adalah korelasi dengan menggunakan pendekatan cross sectional, instrument pengumpulan data menggunakan kuesioner. Sampel dalam penelitian ini sebanyak 94 responden pasien BPJS, dengan menggunakan tekhnik purposive sampling serta menggunakan uji statistik spearman rank.

Hasil penelitian menunjukkan ada hubungan antara perilaku caring perawat dengan kepuasan layanan keperawatan pada pasien BPJS kesehatan di IRNA 3 RSUD Patut Patuh Patju Lombok Barat.

Jika perilaku caring perawat diruang IRNA 3 RSUD Patut Patuh Patju Lombok Barat tinggi maka kepuasan layanan keperawatan yang diterima oleh pasien merasa puas dan begitu sebaliknya apabila perilaku caring perawat pasien kurang baik maka pasien akan merasa kurang merasa dilayani sehingga pasien merasa tidak puas.

Kata Kunci : Perilaku Caring, Layanan Keperawatan, Pasien BPJS kesehatan

\section{THE CORRELATION BETWEEN BEHAVIOR OF NURSES AND SATISFACTION OF NURSING SERVICE FOR PATIENTS OF BPJS FOR HEALTH IN ROOM 3 PATUT PATUH PATJU DISTRICT HOSPITAL WEST LOMBOK}

\author{
Muhammad Asnul Husni ${ }^{1}$, Citra Sepriana ${ }^{2}$, Ageng Abdi Putra ${ }^{3}$, H. Hadi Suryatno ${ }^{4}$ \\ ${ }_{1,2,3,4}$ Sekolah Tinggi Ilmu Kesehatan (STIKES) Mataram \\ muhammadasnulhusni@gmail.com
}

\begin{abstract}
Caring behavior is universal phenomenon affecting human thought, feeling and connection with others. Nurse should own the caring behavior in nursing the patients since the correlation between caring treatment and patient is a factor that affect the recovery of the patient. This research is aimed at determining the correlation between caring behaviour nurses and statisfaction of nursing service for patients of BPJS health in room 3 Patut Patuh Patju District Hospital West Lombok.
\end{abstract}


The research is using correlation method with cross sectional approach. The data were collected through questionnaires from 94 patients of BPJS for health as samples selected through purposive sampling and analyzed with Spearman Rank Statistic test

The research showed that there is correlation between caring behavior of nurses and statisfaction of nursing service for patients of BPJS for health in room 3 Patut Patuh Patju District Hospital West Lombok.

If caring behavior in room 3 patut patuh patju district hospital west Lombok is high, the patients will have good satisfaction, and vice versa, if caring behavior in room 3 patut patuh patju district hospital west Lombok is not good, the patients will have bad satisfaction

Keywords :Caring Behavior, Nursing Care Service, Patients Of BPJS Health

\section{PENDAHULUAN}

Di Indonesia pelayanan kesehatan yang diberikan oleh rumah sakit terus berkembang dan selalu memberikan perubahan yang cepat karena arus era globalisasi yang sedang kita hadapi dibidang kesehatan. Hal tersebut juga berdampak dan berpengaruh penting dalam bidang kesehatan. Petugas kesehatan terutama perawat adalah kunci utama dalam keberhasilan pencapaian tujuan pembangunan kesehatan.

Hal terpenting agar pasien tetap menggunakan jasa rumah sakit tersebut adalah tergantung pada bagaimana pasien tersebut merasa puas dan senang mendapatkan pelayanan (Purwoastuti, 2015).Salah satu tindakan yang diharapkan adalah tenaga perawat dapat membina hubungan baik dengan pasien yaitu dapat melalui teknik dan sikap komunikasi serta berperilaku caring selama memberikan asuhan keperawatan kepada pasien agar kebutuhan pasien dapat terpenuhi.

Perilaku caring merupakan fenomena universal yang mempengaruhi cara manusia berpikir, merasa dan mempunyai hubungan dengan sesama (Potter \& Perry, 2010). Penilaian kepuasan pasien dilihat dari bagian mutu pelayanan karena upaya mutu pelayanan harus dapat memberikan kepuasan, bukan semata- mata untuk kesembuhan pasien saja.Selain itu tingkat kepuasan pasien juga merupakan hal yang penting dalam mengevaluasi kualitas pelayanan yang telah diberikan dari (Sabarguna, 2008). Kepuasan pasien tergantung pada kinerja dalam memberikan suatu pelayanan, bila kinerja jauh lebih rendah daripada harapan pasien, pasien tidak puas dan bila kinerja pelayanan sesuai dengan harapan maka pasien merasa sangat puas atau dapat diartikan sebagai perbandingan antara harapan yang dimiliki oleh pasien dengan kenyataan yang diterima oleh pasien pada saat menerima pelayanan (Kotler, 2008).

Namun, untuk mendapatkan pelayanan kesehatan yang bermutu tersebut, diperlukan biaya yang cukup mahal sehingga bagi masyarakat miskin hal yang sulit untuk diwujudkan. Oleh sebab itu pemerintah melakukan upaya dalam memenuhi hak-hak masyarakat yang seharusnya mereka dapatkan.Salah satu bentuk upaya program pemerintah adalah BPJS (Badan Penyelenggara Jaminan Sosial Kesehatan) yang merupakan badan usaha milik negara yang ditugaskan khusus oleh pemerintah untuk menyelenggarakan jaminan pemeliharaan kesehatan bagi seluruh rakyat Indonesia (Thabrany 2014). Penelitian ini bertujuan untuk mengetahui hubungan perilaku caring perawat dengan kepuasan layanan keperawatan pada pasien BPJS 
kesehatan di IRNA 3 RSUD Patut Patuh Patju Lombok Barat.

\section{METODE PENELITIAN}

Desain peneletian ini menggunakan corelasional study dengan pendekatan cross sectionaldesign. Populasi dalam penelitian ini sebanyak 124 responden, Sampel yang Berdasarkan tabel 1 di atas diperoleh menggunakan purposive sampling sebanyak 94 responden yang telah memenuhi kriteria inklusi dan eksklusi. Penilaian yang digunakan dalam penelitian ini untuk mengukur perilaku caring perawat dan kepuasan layanan keperawatan menggunakan kuesioner. Analisa data yang digunakan dalam penelitian ini adalah uji statistik Spearman Rank .(Sugiyono, 2017).

\section{HASIL}

Tabel 1 Karakteristik Responden menunjukkan bahwa sebagian besar responden pada kelompok yang berusia diantara 45-60 tahun yakni sebanyak 45 responden (47.9\%). Karakteristik responden berdasarkan jenis kelamin perempuan mendominasi sebanyak 49 responden $(52.1 \%)$.

\begin{tabular}{|c|c|c|}
\hline Karakteristik & $\begin{array}{l}\text { Jumlah } \\
(\mathrm{n}=94)\end{array}$ & $\begin{array}{c}\text { Persentase } \\
(\%)\end{array}$ \\
\hline $\begin{array}{ll}\text { A. Usia } \\
\text { 1. } 18-30 \text { Tahun } \\
\text { 2. } \quad 31-44 \text { Tahun } \\
\text { 3. } \quad 45-60 \text { Tahun }\end{array}$ & $\begin{array}{l}23 \\
26 \\
45\end{array}$ & $\begin{array}{l}24,5 \% \\
27,7 \% \\
47,9 \%\end{array}$ \\
\hline B. Jenis Kelamin & & \\
\hline $\begin{array}{ll}\text { 1. } & \text { Laki-laki } \\
\text { 2. } & \text { Perempuan }\end{array}$ & $\begin{array}{l}45 \\
49\end{array}$ & $\begin{array}{l}47,9 \% \\
52,1 \%\end{array}$ \\
\hline $\begin{array}{l}\text { C. Pekerjaan } \\
\text { 1. } \quad \text { Buruh } \\
\text { 2. Petani } \\
\text { 3. IRT } \\
\text { 4. Wiraswasta } \\
\text { 5. } \text { Pelajar }\end{array}$ & $\begin{array}{l}25 \\
21 \\
19 \\
17 \\
12\end{array}$ & $\begin{array}{l}26,6 \% \\
22,3 \% \\
20,2 \% \\
18,1 \% \\
12,8 \%\end{array}$ \\
\hline $\begin{array}{l}\text { D. Pendidikan } \\
\text { 1. Tidak Sekolah } \\
\text { 2. SD } \\
\text { 3. SMP }\end{array}$ & $\begin{array}{l}14 \\
38 \\
12 \\
28 \\
2\end{array}$ & $\begin{array}{l}14,9 \% \\
40,4 \% \\
12,8 \% \\
29,8 \% \\
2,1 \%\end{array}$ \\
\hline
\end{tabular}

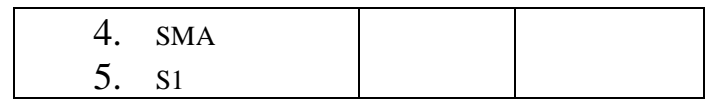

Karakteristik responden berdasarkan pekerjaan menunjukkan bahwa sebagian besar responden bekerja sebagai buruh yaitu sebanyak 25 responden (26.6\%). Karakteristik responden berdasarkan pendidikan menunjukkan bahwa sebagian besar responden berpendidikan SD sebanyak 38 responden (40.4\%).

Tabel 2 Identifikasi tanggapan reponden terhadap perilaku caring perawat di IRNA 3 RSUD Patut Patuh Patju Lombok Barat

\begin{tabular}{|c|c|c|c|}
\hline No & $\begin{array}{c}\text { Perilaku Caring } \\
\text { Perawat }\end{array}$ & Jumlah & $\begin{array}{c}\text { Persentase } \\
(\%)\end{array}$ \\
\hline 1 & Baik & 12 & $12.8 \%$ \\
\hline 2 & Cukup & 72 & $76.6 \%$ \\
\hline 3 & Kurang & 10 & $10.6 \%$ \\
\hline & Total & 94 & $100 \%$ \\
\hline
\end{tabular}

Berdasarkan tabel 2 di atas, menunjukkan bahwa sebagian besar responden memberikan tanggapan bahwa perilaku caring perawat sebagian besar dalam kriteria cukup sebanyak 72 responden $(76.6 \%)$.

Tabel 3 Identifikasi Kepuasan layanan keperawatan pada pasien BPJS kesehatan di IRNA 3 RSUD Patut Patuh Patju Lombok Barat

\begin{tabular}{|c|c|c|c|}
\hline No & $\begin{array}{c}\text { Kepuasan } \\
\text { Layanan } \\
\text { Keperawatan }\end{array}$ & Jumlah & $\begin{array}{r}\text { Persentas } \\
\text { e }(\%)\end{array}$ \\
\hline 1 & Sangat Puas & 15 & $16.0 \%$ \\
\hline 2 & Puas & 78 & $83.0 \%$ \\
\hline 3 & Tidak Puas & 1 & $1.1 \%$ \\
\hline & Total & 94 & 100,0 \\
\hline
\end{tabular}
menunjukkan bahwa sebagian besar responden merasa puas dengan layanan keperawatan sebanyak 78 responden $(83.0 \%)$

Tabel 4 Hubungan Perilaku Caring Perawat Dengan Kepuasan Layanan Keperawatan Pada Pasien BPJS Kesehatan di IRNA 3 RSUD Patut Patuh Patju Lombok Barat 


\begin{tabular}{|c|c|c|c|c|c|c|c|c|}
\hline \multirow{3}{*}{$\begin{array}{l}\text { Caring } \\
\text { Perawat }\end{array}$} & \multicolumn{6}{|c|}{ Kepuasan Layanan } & \multirow{2}{*}{\multicolumn{2}{|c|}{ Total }} \\
\hline & \multicolumn{2}{|c|}{$\begin{array}{c}\text { Tidak } \\
\text { Puas } \\
\end{array}$} & \multicolumn{2}{|c|}{ Puas } & \multicolumn{2}{|c|}{$\begin{array}{c}\text { Sangat } \\
\text { puas }\end{array}$} & & \\
\hline & $\mathrm{F}$ & $\%$ & $\mathrm{~F}$ & $\%$ & $\mathrm{~F}$ & $\%$ & $\mathrm{~F}$ & $\%$ \\
\hline Kurang & 1 & 1 & 9 & 10 & 0 & 0 & 10 & 10 \\
\hline Cukup & 0 & 0 & 62 & 66 & 10 & 11 & 72 & 77 \\
\hline Baik & 0 & 0 & 7 & 7 & 5 & 5 & 12 & 13 \\
\hline Total & 1 & 1 & 78 & 83 & 15 & 16 & 94 & 100 \\
\hline \multicolumn{9}{|c|}{$\begin{array}{l}p \text {-value uji Spearman-Rank } \\
0,002\end{array}$} \\
\hline \multicolumn{9}{|c|}{$\begin{array}{c}\text { Cofecient correlation } \\
0,321\end{array}$} \\
\hline
\end{tabular}

Berdasarkan tabel 2 di atas, menunjukkan bahwa sebagian besar responden memberikan tanggapan bahwa perilaku caring perawat sebagian besar dalam kriteria cukup sebanyak 72 responden $(76.6 \%)$.

Tabel 3 Identifikasi Kepuasan layanan keperawatan pada pasien BPJS kesehatan di IRNA 3 RSUD Patut Patuh Patju Lombok Barat

Berdasarkan tabel 4 di atas, Berdasarkan tabel 3 di atas, menunjukkan bahwa hasil uji Spearman-Rank diperoleh nilai signifikansi sebesar $0,002 \quad(\mathrm{p}<0,05)$ dan coefficient correlation sebesar 0,321. Pembahasan Berdasarkan tabel 2 menunjukkan bahwa sebagian besar responden menunjukkan bahwa sebagian besar responden merasa puas dengan layanan keperawatan sebanyak 78 responden (83.0\%) memberikan tanggapan bahwa perilaku caring perawat sebagian besar dalam kriteria cukup sebanyak 72 responden $(76.6 \%)$. Ditinjau dari hasil penelitian karakteristik responden dari segi pekerjaan dan pendidikan pada tabel 1. Dimana sebagian besar responden bekerja sebagai buruh yaitu sebanyak 25 responden (26.6\%). Menurut Situmpol (2012), masyarakat yang bekerja, lebih cenderung dipengaruhi oleh lingkungan pekerjaan. Oleh karna itu orang yang bekerja lebih cenderung menuntut dan mengkritik pelayanan yang diberikan. Dari segi pendidikan menunjukkan bahwa sebagian besar responden berpendidikan
SD sebanyak 38 responden (40.4\%). Pendidikan sangat berpengaruh terhadap pengetahuan seseorang yang dimana semakin tinggi pendidikan seseorang maka pengetahuan seseorang itu semakin tinggi. Menurut Lestari (2008) Semakin tinggi tingkat pendidikan seseorang, maka semakin meningkat daya mengkritisi segala sesuatu, sehingga seseorang dengan pendidikan yang lebih tinggi akan lebih kritis dalam menentukan apakah pelayanan yang diberikan terasa puas atau tidak.

Caring merupakan bentuk dasar dari praktik keperawatan yang dimana membantu klien untuk pulih dari sakitnya, memberikan penjelasan tentang penyakitnya, dan mengelola atau membangun kembali hubungan antara perawat dengan klien (Potter \& Perry 2010). Perilaku caring merupakan hal yang penting bagi pasien sebagai pengguna jasa dalam layanan keperawatan, yang akan membantu salah satu dari proses kesembuhan pasien itu sendiri (Manurung, S 2013). Hal ini sesuai dengan penelitian Eka Febri Marmi (2015) tentang hubungan beban kerja dengan perilaku caring perawat menurut persepsi klien di IGD RS PKU Muhammadiyah Yogyakarta yang menunjukkan hasil bahwa sebagian besar perilaku caring perawat termasuk dalam kriteria cukup sebanyak 13 responden dengan presentase $72.2 \%$.

Berdasarkan tabel 3 menunjukkan bahwa layanan keperawatan yang diberikan pada pasien BPJS kesehatan di ruang IRNA 3 RSUD Patut Patuh Patju Lombok Barat sebagian besar dalam kriteria puas sebanyak 78 responden (83.0\%). Ditinjau dari hasil penelitian karakteristik responden dari segi umur dan jenis kelamin pada tabel 1. Dimana sebagaian besar responden pada kelompok yang berusia diantara 45-60 tahun yakni sebanyak 45 responden (47.9\%). Usia adalah umur individu yang terhitung mulai saat dilahirkan sampai 
berulang tahun, semakin bertambahnya usia semakin cukup juga tingkat kematangan dan kekuatan seseorang yang lebih matang dan bekerja dan berfikir dan hal ini juga dipercaya oleh masyarakat dari segi kedewasaan seseorang berdasarkan umur mereka, usia lebih tua lebih puas terhadap layanan kesehatan yang diberikan karena usia muda lebih menuntut pelayanan agar lebih baik lagi (Wong, 2009). Dari segi jenis kelamin menunjukkan bahwa jenis kelamin perempuan mendominasi sebanyak 49 responden (52.1\%). Menurut Situmpol (2012) mengatakan bahwa jenis kelamin wanita cenderung puas terhadap pelayanan daripada laki-laki, hal tersebut karna sifat peserta dengan jenis kelamin laki-laki cenderung dominan, aktif dan bebas ditunjukkan dengan sifat percaya diri, terus terang, keras, kompetetif dan yakin.

Kepuasan layanan keperawatan juga tergantung pada kinerja dalam memberikan suatu pelayanan, bila kinerja jauh lebih rendah dari pada harapan pasien, pasien tidak puas dan bila kinerja pelayanan sesuai dengan harapan maka pasien merasa sangat puas atau dapat diartikan sebagai perbandingan antara harapan yang dimiliki oleh pasien dengan kenyataan yang diterima oleh pasien pada saat menerima pelayanan (Kotler, 2008). Hasil Penelitian ini didukung dengan hasil penelitian yang dilakukan oleh Widyasih (2014) yang berjudul persepsi masyarakat terhadap pelayanan BPJS di RSI kendal yang dimana dalam penelitiannya menunjukkan hasil bahwa sebagian besar responden mempunyai persepsi baik terhadap pelayanan BPJS yaitu sebanyak 97 responden $(45,1 \%)$.

Berdasarkan tabel 4 menunjukkan bahwa Hasil uji spearman rank didapatkan $P$ value $=0,002$ yang berarti bahwa nilai $\mathrm{p}$ value lebih kecil dari nilai alpha $(\mathrm{P}<\alpha)$ dengan $\alpha=0.05$ yang artinya $\mathrm{Ha}$ diterima yang diartikan bahwa ada hubungan antara perilaku caring perawat dengan kepuasan layanan keperawatan pada pasien BPJS kesehatan di IRNA 3 RSUD Patut Patuh Patju Lombok Baratdandidapatkan hasil koefisien korelasi sebesar 0,321 maka dengan ini menandakan bahwa ada koefisien korelasi yang cukup antara perilaku caring perawat dengan kepuasan layanan keperawatan pada pasien BPJS kesehatan.

Hal ini mengindikasikan bahwa semakin baik perilaku caring perawat ketika memberikan layanan keperawatan kepada pasien BPJS maka akan semakin tinggi pula tingkat kepuasan yang dirasakan oleh pasien. Pernyataan ini didukung teori yang dikemukakan oleh Singgih\& Yulia (2012), bahwa perawat yang dapat meyakinkan pasien atau keluarga akan memperoleh kepercayaan dari pasien, sehingga secara tidak langsung dapat membantu membentuk sikap positif pasien terhadap perawat, ada orang sakit yang ingin selalu diperhatikan dan menarik perhatian perawat, ada pula pasien yang sungkan dan segan untuk memanggil dan meminta bantuan perawat.

Berdasarkan beberapa teori dan hasil penelitian tentang perilaku caring perawat dengan kepuasan pasien sangat erat hubungannya karena perlakuan perawat sebagai provider dimana pelayanan perawat harus dapat dirasakan dan memberikan dampak yang positif terhadap pasien sebagai customer (pelanggan) pelayanan kesehatan dirumah sakit (Ilkafah\& Harnia, 2017).

\section{SIMPULAN}

Berdasarkan penelitian, maka dapat dikemukakan kesimpulan ada hubungan perilaku caring perawat dengan kepuasan layanan keperawatan pada pasien BPJS kesehatan di IRNA 3 RSUD Patut Patuh Patju Lombok Barat. Karena seorang perawat harus memiliki 


\section{DAFTAR PUSTAKA}

terhadap pasien, karena hubungan antara pemberi pelayanan kesehatan dengan pasien merupakan faktor yang mempengaruhi proses kepuasan dan kesembuhan pasien tersebut
Eka Febri Marmi 2015 Tentang Hubungan Hubungan Beban Kerja Dengan Perilaku Caring Perawat Menurut Persepsi Klien Di IGD RS PKU Muhammadiyah Yogyakarta. Skripsi. Stikes Aisyiyah Yogyakarta

Ilkafah, 2017. Perilaku Caring Perawat Dengan Kepuasan Pasien Di Ruang Rawat Inapprivate Care Centre RSUP Dr Wahidin Sudirohusodo Makassar. Jurnal.Universitas Hasanuddin.

Kotler, P. 2008. Marketing Management: Analysis, Planning, Implementation And Control. New Jersey: Prentice Hall.

Lestari, P. Sunarto dan Kuntari.(2008). Analisa Penentu Tingkat KepuasanPasien di Rumah Sakit PKUMuhammadiyah Bantul.Jurnal Kedokteran dan Kesehatan Indonesia.

Manurung S , 2013. Persepsi pasien terhadap perilaku caring di ruang rawat inap rumah sakit.

Nursalam, 2017. Metode Penelitian Ilmu Keperawatan Pendekatan Praktis Edisi Ke 4. Jakarta : Salemba Medika.

Potter \& perry, 2010.Fundamental keperawatan.Edisi 7.Jakarta : salemba medika.

Purwoastuti. 2015. Perilaku dan Softskills Kesehatan Panduan Untuk Tenaga Kesehatan (Perawat dan Bidan). Yogyakarta: Pustaka baru press

Sabarguna, B.S. 2008, Quality Assurance Rumah Sakit, Sagung Seto, Jakarta

Thabrany, Hasbullah. 2014. Jaminan Kesehatan Nasional.PT.

Rajagrafindo Persada. Jakarta

Singgih,\& Yulia. 2012. Psikologi Keperawatan. Jakarta: Libri.

Sugiyono, 2017. Statistika Untuk 
Penelitian. Bandung : Alfabeta

Widyasih, E., Mubin, M. F., \& Hidyati,

E. (2014). Persepsi Masyarakat

Terhadap Pelayanan BPJS di RSI

Kendal. Prosiding Konferensi

Nasional II PPNI JawaTengah , 274-279.

Wong, D.L. 2009.Buku Ajar

Keperawatan Pediatrik Volume 2.

Jakarta : EGC. 